\title{
Rapid and simple method for extraction and determination of imidazolinone herbicides in soil
}

\author{
G. D’Ascenzo*, A. Gentili, S. Marchese, A. Marino and D. Perret
}

\author{
Dipartimento di Chimica, Università “La Sapienza” di Roma, Piazzale Aldo Moro n5, 00185 Rome, Italy
}

\begin{abstract}
A rapid, simple and accurate method for the simultaneous determination of residues of the imidazolinone herbicides (imazapyr, imazaquin, imazamethabenz and imazamethabenz-methyl) in soil is described. The basis of the method is the formation of a supernatant by sonication of the soil with $0.1 \mathrm{M} \mathrm{KCl}$. After removal from the soil particles, the pesticides are quantified by reversed-phase liquid chromatography-mass spectrometry with an electrospray interface (LC-ESI-MS). Recoveries from a variety of soil types, fortified over the range of $50-200 \mathrm{ppb}$, are essentially quantitative for each imidazolinone and the detection limits (signal-to-noise ratio $=3$ ) of the method are always lower than $14 \mathrm{ng} / \mathrm{g}$.
\end{abstract}

Key words. Residues — imidazolinone herbicides — soil LC/ESI/MS. 


\section{Introduction}

A certain proportion of all pesticides used in agriculture reaches the soil. Even when the pesticides are applied to plant foliage, the soil acts as a major reservoir and site of potential degradation. It is known that when some pesticides, or their degradation products, enter the soil they become bound to the organic matter or clay mineral soil [1]. Because of the difficulties involved in extraction and identification, it has generally only been possible to demonstrate the presence of these soil-bound residues using radiolabeled pesticides [2].

Since pesticides are toxic by nature, there is a natural concern about the impact of their presence in the environment on human health and environmental quality. Moreover, it is well known that several pesticides used for agricultural purposes are associated with surface and groundwater contamination [3]. Therefore, it is important to be able to predict the fate of pesticide residues in the environment, and optimization of their extraction is a key step towards this goal.

The imidazolinones are a significant new class of lowuse-rate herbicides for the protection of a wide variety of agricultural commodities [4]. They were discovered and introduced by American Cyanamid. As shown in figure 1, the members of this class of herbicides have similar structural features centered around the imidazolinone ring and attached aromatic system bearing a carboxylic acid moiety [5]. In general the imidazolinones are highly active against annual and perennial grasses and broad-leaved weeds when applied either pre- or postemergence.

Current analytical methodologies for the determination of imidazolinones in soil are targeted at individual members of the group and are usually very tedious [6-8]. Furthermore, because of their low application dosage, the monitoring of imidazolinone residues in soil has to be performed at the ppb level.

The present paper describes a simple and effective procedure for extracting from soil the entire class of imidazolinones. When combined with liquid chromatography-electrospray mass spectrometry the procedure allows even very small quantities of analytes to be determined.

The procedure is reliable enough to used as a routine analytical method.

\section{Experimental}

\section{Reagents}

Authentic imidazolinone herbicides were purchased from LabService (Bologna, Italy). Individual standard solutions were prepared by dissolving $100 \mathrm{mg} / \mathrm{L}$ of each analyte in water. The resulting solutions were then further diluted to obtain two $10 \mathrm{mg} / \mathrm{L}$ and $5 \mathrm{mg} / \mathrm{L}$ working standard solutions, respectively. All standard solutions were stored at $4{ }^{\circ} \mathrm{C}$ prior to use.

For LC, distilled water was further purified by passing it through the Milli-Q Plus apparatus (Millipore, Bedford, MA, USA). Gradient grade acetonitrile "plus" was obtained from Carlo Erba (Milan, Italy). Potassium chloride, sodium chlo-

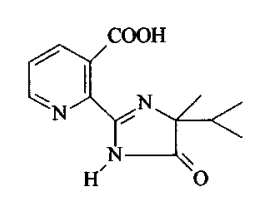

IMAZAPYR

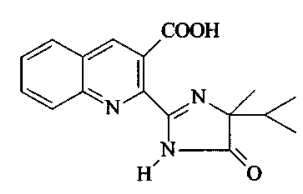

IMAZAQUIN

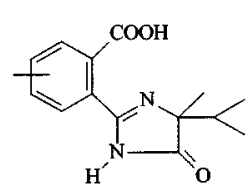

$m-p$ IMAZAMETHABENZ

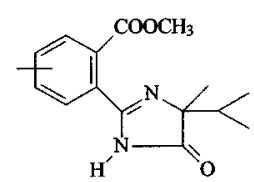

$m-p$ IMAZAMETHABENZ Methyl
Fig. 1. Structure and common name of imidazolinone herbicides.

ride, formic acid and other solvents, used as supplied, were of analytical grade (Carlo Erba).

\section{Apparatus}

For extraction purposes a T 490 model Transonic sonicator (Bracco, Rome, Italy) and a vacuum filtering apparatus from Millipore (Bedford, MA, USA) equipped with $0.45 \mu \mathrm{m}$ nylon filter membranes (Alltech, Milan, Italy) were used.

\section{Soil fortification}

The soils tested were taken from five different Italian sites. They were selected on the basis of several physico-chemical parameters (Tab. I). Soil samples were collected at a depth of $15-30 \mathrm{~cm}$ layer in the soil profile and passed through a $2 \mathrm{~mm}$ sieve. The samples were kept at $4{ }^{\circ} \mathrm{C}$ prior to use.

Fortified samples were provided by spiking $5 \mathrm{~g}$ of dried soil with a known volume of working standard solution to obtain levels of 50, 100 and $200 \mathrm{ng} / \mathrm{g}$. The soil was then homogenized by shaking for $30 \mathrm{~min}$ and the bulk of the solvent was evaporated in a ventilated oven at $40{ }^{\circ} \mathrm{C}$ until the material appeared dry.

Unspiked soils were used as controls.

\section{Extraction procedure}

A $20 \mathrm{~mL}$ aliquot of potassium chloride $0.1 \mathrm{M}$ was added to the soil samples and the mixture shaken for $10 \mathrm{~min}$ in a mechanical shaker. Subsequently the solvent/soil suspension

Table I. Physico-chemical properties of soils.

\begin{tabular}{lccccccc}
\hline Soil & $\begin{array}{c}\text { Textural } \\
\text { class }\end{array}$ & $\begin{array}{c}\text { Organic } \\
\text { matter (\%) }\end{array}$ & $\begin{array}{c}\text { Clay } \\
(\%)\end{array}$ & $\begin{array}{c}\text { Sand } \\
(\%)\end{array}$ & $\begin{array}{c}\text { Silt } \\
(\%)\end{array}$ & $\begin{array}{c}\text { pH } \\
\text { C.E.C. } \\
(\mathrm{meq} / \\
100 \mathrm{~g})\end{array}$ \\
\hline CO & clay & 18.1 & 49.6 & 35.8 & 14.6 & 5.2 & 18.1 \\
PO & clay loam & 3.8 & 37.6 & 22.6 & 39.8 & 7.6 & 29.4 \\
CA sandy clay loam & 1.4 & 29.1 & 47.3 & 23.6 & 6.8 & 26.1 \\
LT & silty loam & 2.2 & 22.1 & 24.5 & 53.4 & 5.9 & 10.3 \\
CP & sandy loam & 3.2 & 17.6 & 54.2 & 28.2 & 6.2 & 27.5 \\
\hline
\end{tabular}

a Cation exchange capacity. 
Table II. Preliminary evaluation of extractants.

\begin{tabular}{|c|c|c|c|c|c|}
\hline $\begin{array}{l}\text { Recovery }(\%)^{1} \\
\text { Extraction solution }\end{array}$ & Soil & Imazapyr $^{2}$ & Imazamethabenz $^{2}$ & $\begin{array}{c}\text { Imazamethabenz } \\
\text { Methyl }^{2}\end{array}$ & Imazaquin $^{2}$ \\
\hline $\mathrm{H}_{2} \mathrm{O}$ & $\begin{array}{l}\mathrm{PO} \\
\mathrm{CO} \\
\mathrm{CA} \\
\mathrm{CP} \\
\mathrm{LT}\end{array}$ & $\begin{array}{l}58 \\
50 \\
52 \\
68 \\
50\end{array}$ & $\begin{array}{l}59 \\
52 \\
56 \\
76 \\
61\end{array}$ & $\begin{array}{l}74 \\
67 \\
69 \\
81 \\
62\end{array}$ & $\begin{array}{l}70 \\
53 \\
65 \\
77 \\
65\end{array}$ \\
\hline $\begin{array}{l}\mathrm{MeOH} / \mathrm{H}_{2} \mathrm{O} \\
50: 50(\mathrm{v} / \mathrm{v})\end{array}$ & $\begin{array}{l}\mathrm{PO} \\
\mathrm{CO} \\
\mathrm{CA} \\
\mathrm{CP} \\
\mathrm{LT}\end{array}$ & $\begin{array}{l}63 \\
55 \\
61 \\
74 \\
55\end{array}$ & $\begin{array}{l}57 \\
49 \\
55 \\
71 \\
74\end{array}$ & $\begin{array}{l}60 \\
56 \\
57 \\
68 \\
59\end{array}$ & $\begin{array}{l}65 \\
48 \\
62 \\
66 \\
53\end{array}$ \\
\hline $\begin{array}{l}\mathrm{MeOH} / \mathrm{H}_{2} \mathrm{O} \\
80: 20(\mathrm{v} / \mathrm{v})\end{array}$ & $\begin{array}{l}\text { PO } \\
\text { CO } \\
\text { CA } \\
\text { CP } \\
\text { LT }\end{array}$ & $\begin{array}{l}66 \\
61 \\
64 \\
75 \\
68\end{array}$ & $\begin{array}{l}61 \\
42 \\
59 \\
67 \\
56\end{array}$ & $\begin{array}{l}52 \\
45 \\
51 \\
62 \\
58\end{array}$ & $\begin{array}{l}59 \\
40 \\
57 \\
65 \\
67\end{array}$ \\
\hline $\begin{array}{l}\mathrm{NaCl} \\
0.1 \mathrm{M}\end{array}$ & $\begin{array}{l}\text { PO } \\
\text { CO } \\
\text { CA } \\
\text { CP } \\
\text { LT }\end{array}$ & $\begin{array}{l}78 \\
69 \\
75 \\
83 \\
74\end{array}$ & $\begin{array}{l}76 \\
71 \\
68 \\
87 \\
79\end{array}$ & $\begin{array}{l}81 \\
77 \\
73 \\
88 \\
76\end{array}$ & $\begin{array}{l}79 \\
67 \\
69 \\
78 \\
73\end{array}$ \\
\hline
\end{tabular}

${ }^{1}$ Mean values from five determinations, RDS are less than $10 \%$ in every case.

${ }^{2}$ Spike le vel $100 \mathrm{ng} / \mathrm{g}$.

Table III. Recovery and RSD of imidazolinone herbicides from soil samples at three different spike level using $\mathrm{KCl} 0.1 \mathrm{M}$ extractant.

\begin{tabular}{|c|c|c|c|c|c|}
\hline \multicolumn{3}{|l|}{ spike level $50 \mathrm{ng} / \mathrm{g}$} & \multicolumn{3}{|c|}{ Recovery $(\%)^{1} \pm R S D$} \\
\hline Herbicide & soil PO & soil $\mathrm{CO}$ & soil CA & soil CP & soil LT \\
\hline Imazapyr & $93 \pm 6$ & $90 \pm 8$ & $96 \pm 4$ & $92 \pm 6$ & $92 \pm 6$ \\
\hline Imazamethabenz & $89 \pm 7$ & $91 \pm 5$ & $93 \pm 5$ & $90 \pm 5$ & $87 \pm 5$ \\
\hline Imazamethabenz Methyl & $80 \pm 5$ & $89 \pm 7$ & $94 \pm 4$ & $89 \pm 4$ & $93 \pm 7$ \\
\hline Imazaquin & $88 \pm 5$ & $98 \pm 6$ & $95 \pm 6$ & $99 \pm 5$ & $88 \pm 8$ \\
\hline \multicolumn{3}{|l|}{ spike level $100 \mathrm{ng} / \mathrm{g}$} & \multicolumn{3}{|c|}{ Recovery $(\%)^{l} \pm R S D$} \\
\hline Herbicide & soil PO & soil $\mathrm{CO}$ & soil CA & soil $\mathrm{CP}$ & soil LT \\
\hline Imazapyr & $95 \pm 5$ & $93 \pm 5$ & $90 \pm 5$ & $92 \pm 4$ & $90 \pm 7$ \\
\hline Imazamethabenz & $92 \pm 6$ & $88 \pm 7$ & $95 \pm 4$ & $91 \pm 6$ & $94 \pm 6$ \\
\hline Imazamethabenz Methyl & $81 \pm 7$ & $92 \pm 5$ & $91 \pm 5$ & $87 \pm 7$ & $87 \pm 7$ \\
\hline Imazaquin & $90 \pm 5$ & $88 \pm 5$ & $88 \pm 4$ & $95 \pm 6$ & $95 \pm 8$ \\
\hline \multicolumn{3}{|l|}{ spike level $200 \mathrm{ng} / \mathrm{g}$} & \multicolumn{3}{|c|}{ Recovery $(\%)^{l} \pm R S D$} \\
\hline Herbicide & soil PO & soil CO & soil CA & soil CP & soil LT \\
\hline Imazapyr & $91 \pm 5$ & $93 \pm 6$ & $92 \pm 5$ & $89 \pm 7$ & $93 \pm 5$ \\
\hline Imazamethabenz & $89 \pm 6$ & $87 \pm 7$ & $94 \pm 5$ & $96 \pm 7$ & $95 \pm 4$ \\
\hline Imazamethabenz Methyl & $83 \pm 5$ & $86 \pm 6$ & $98 \pm 4$ & $94 \pm 5$ & $96 \pm 6$ \\
\hline Imazaquin & $91 \pm 7$ & $93 \pm 5$ & $95 \pm 4$ & $91 \pm 4$ & $90 \pm 7$ \\
\hline
\end{tabular}

${ }^{1}$ Mean values for five determinations.

was sonicated for $15 \mathrm{~min}$ and then centrifuged at $2000 \mathrm{~g}$ for $10 \mathrm{~min}$. The entire procedure was repeated twice on the same soil sample. Lastly, the extracts were combined and vacuum filtered. $20 \mu \mathrm{L}$ of the final extract were injected into the LC column.

\section{LC-ESI-MS analysis}

LC was carried out using a Perkin-Elmer series 200 binary pump (Perkin-Elmer, Norwalk, CT, USA) equipped with a Rheodyne 7125 injector with a $20 \mu \mathrm{L}$ loop and a Perkin- 
Elmer Series 200 Vacuum Degasser. The analytes were chromatographed on an Alltima $25 \times 4.6 \mathrm{~mm}$ I.D. column filled with $5 \mu \mathrm{m} \mathrm{C}_{18}$ reversed-phase packing (Alltech, Deerfield, IL, USA). For the purpose of fractionating the analytes, acetonitrile was selected as phase A and water as phase B. Both solvents contained $100 \mathrm{mM} \mathrm{HCOOH}$. Gradient elution was performed by linearly increasing the percentage of organic modifier from 10 to $60 \%$ in $20 \mathrm{~min}$. The flow-rate of the mobile phase was $1 \mathrm{~mL} / \mathrm{min}$. A $50 \mu \mathrm{L}$ portion of column effluent was diverted to the ES source. ESI-MS was performed on a Perkin-Elmer/Sciex API I single-stage quadruple instrument equipped with a TurboIonspray interface (Sciex, Thornton, Canada). The mass spectrometer was operated in positive ion mode by applying a voltage of $5000 \mathrm{~V}$ to the capillary. The orifice plate was set at $90 \mathrm{~V}$ and the interface temperature at $62{ }^{\circ} \mathrm{C}$. Mass spectra were acquired in time-scheduled selected ion monitoring (SIM) mode. For recovery studies the concentrations of the analytes were calculated by measuring peak areas from extracted-ion current (XIC) profiles and comparing them with those obtained from standard solutions [9]. For any given analyte, the selected XIC was that obtained from the most abundant ion. Peak area ratio for selected ions was determined using the PE Sciex package MacQuan 1.3.

\section{Results and discussion}

\section{Preliminary experiments}

The development of a new extraction method entails investigating the effect of single factors on the analytical procedure. In our case, the optimal conditions for obtaining maximum recovery were determined by carrying out a series of preliminary experiments. First, an extracting solution was identified that was effective for different soils ranging from sandy loam which, with its high sand content generally does not give rise to significant interactions, to clay and clay loam in which high pesticide adsorption can instead be found. At the same time the stability of the individual analytes was tested in the various extracting solutions exposed to ultrasounds. All four imidazolinones were found to be stable in neutral medium while in acidic medium $(\mathrm{pH}<5)$ and especially in alkaline medium $(\mathrm{pH}>8)$ imazamethabenz-methyl was found to undergo rapid hydrolysis. These results thus influenced the choice of extracting solution by restricting the field of investigation to neutral solutions. Tests were subsequently run on the effects due to the volume of the extracting solution and to sonication time on herbicide recovery. The best results were obtained with a soil-solution ratio of 1:4 with a sonication step of $15 \mathrm{~min}$. In order to obtain repeatable quantitative yields two extraction cycles were necessary, especially for the soil $\mathrm{CO}$ which, in agreement with literature data $[7,10]$, displayed higher analyte adsorption due to the higher clay and organic substance content and its lower $\mathrm{pH}$.

The supernatant was removed from the soil/solution suspension after ultrasonic treatment by means of centrifuging followed by vacuum filtering. This procedure rapidly afforded a clear final extract that needed no further clean-up and that could be injected directly into the chromatography column. Centrifuging alone does not in fact always guarantee removal of all the fine clay particles, while filtering the suspension is complicated by the blocking of the pores of the filtering membrane. This prolongs the total analysis time, increases the cost and significantly impairs recovery.
The results of the preliminary experiments carried out as described above, using different extracting solutions, are shown in table II. The results show that extraction with methanol/water solution $80: 20(\mathrm{v} / \mathrm{v})$ is more effective than extraction with water or with methanol/water 50:50 (v/v) in the case of imazapyr. Conversely, for the other three analytes, and in particular for imazamethabenz-methyl, recoveries are found to decrease with increasing methanol content in the mixture. One plausible explanation of this trend is that imazapyr is more soluble in methanol than in more polar solvents [8] compared with the other imidazolinones.

An evaluation was made also of extraction using organic solvents such as pure methanol and acetone (unpublished results) although the recoveries proved to be largely unsatisfactory.

Sodium chloride solution $0.1 \mathrm{M}$ proved to have a good extractive power for all the analytes, although the best results were obtained using potassium chloride $0.1 \mathrm{M}$ (Tab. III) as extracting solution. The final test performed was to vary $\mathrm{KCl}$ concentration from 0.1 to $1 \mathrm{M}$ although no significant variation in recovery was observed.

\section{Optimal conditions}

Optimal conditions for maximum pesticide recovery proved to be: extracting solution $\mathrm{KCl} 0.1 \mathrm{M}$, soil/solution ratio of $1: 4$, two extraction cycles in each of which the sonication step lasted $15 \mathrm{~min}$.

The recoveries and relative standard deviations of the imidazolinones added to the soil samples at different concentrations are shown in table III. As can be seen, the composition of the five soil samples analysed and the fortification levels used $(50,100,200 \mathrm{ng} / \mathrm{g})$ had no apparent effect on the experimental results, which is extremely encouraging for the applicability of the proposed extraction method.

Also the repeatability of the procedure is good, the relative standard deviation (RSD) is less than $10 \%$ (Tab. III) for all analytes.

\section{LC-ESI-MS conditions}

Using LC-ESI-MS each imidazolinone essentially generated only one $\mathrm{M}+\mathrm{H}^{+}$ion.

In a previous paper [11] we described both the effect on signal strength of the variation in proton concentration in the LC mobile phases, together with the effect of varying the orifice plate (OR) voltage on signal strength and on the production of ion fragments. The results show that maximum fragmentation spectra and signal repeatability are achieved when both the LC mobile phases contain $\mathrm{HCOOH}$ at a concentration of $100 \mathrm{mM}$. As far as specificity is concerned, abundant $\mathrm{M}+\mathrm{H}^{+}$fragmentation of the analyte ions is obtained by varying the OR voltage between 90 and $110 \mathrm{~V}$. $\mathrm{OR}=90 \mathrm{~V}$ was selected as operating condition.

The conditions of the time scheduled SIM for monitoring the four imidazolinones are shown in table IV. Figure 2 contains a time scheduled SIM chromatogram and XIC profiles of the final extract referring to a soil sample spiked with the herbicides at a level of $50 \mathrm{ng} / \mathrm{g}$. As can be seen, despite the complexity of the matrix, the sensitivity obtained via time scheduled SIM acquisition is particularly high [9]. The limits of detection (LODs) calculated using a signal-to-noise 

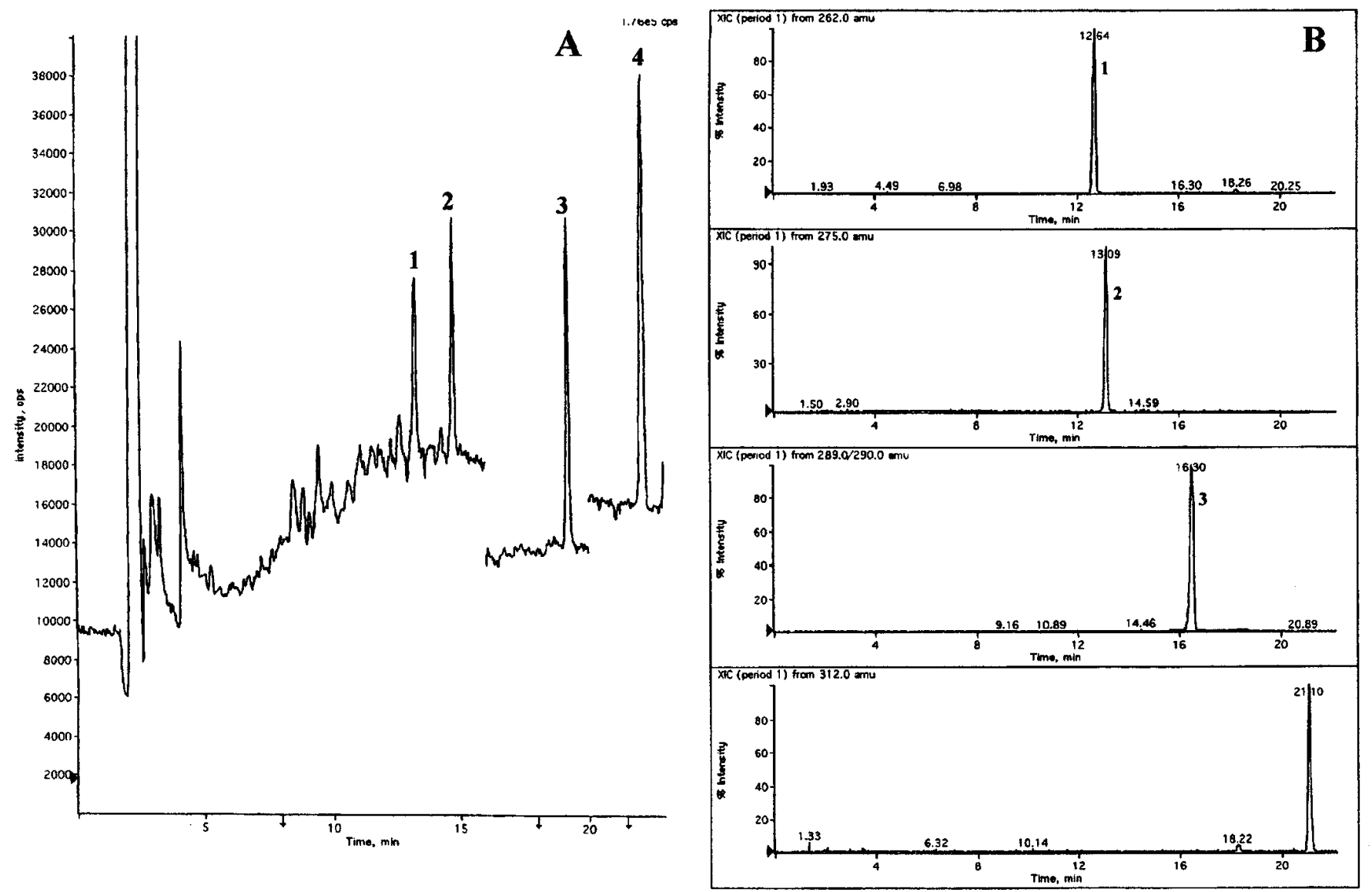

Fig. 2. A) Time-Scheduled SIM and B) extract ion current (XIC) profile of the imidazolinones obtained by injecting $20 \mu \mathrm{L}$ of PO soil spiked with $50 \mathrm{ng} / \mathrm{g}$ each. (1) imazaquin, (2) imazamethabenz, (3) imazamethabenz methyl, (4) imazapyr.

Table IV. Time-Scheduled SIM conditions for monitoring imidazolinone herbicides in soil ${ }^{\mathrm{a}}$.

\begin{tabular}{llc}
\hline Herbicide & $\begin{array}{l}\text { Channel mass, } \mathrm{m} / \mathrm{z}^{b} \\
\text { (relative abundance) }\end{array}$ & $\begin{array}{c}\text { Retention } \\
\text { windows } \\
\text { (min) }\end{array}$
\end{tabular}

Imazapyr 149 (74), 202 (62), 262 (100) $0-16$

Imazamethabenz $162(81), 215$ (46), 275 (100)

Imazamethabenz Methyl 162 (74), 229 (82), 289 (100) $16-21$

Imazaquin 199 (40), 267 (47), 312 (100) $21-25$

${ }^{a}$ Dwell Time: $0.1 \mathrm{~s}$; width: 1 ; OR $=90 \mathrm{~V}$.

${ }^{\mathrm{b}}$ Protonated molecular ions are reported in bold.

Table V. Limit of detection (LOD, ng/g in soil) of imidazolinone herbicides obtained in Time-Scheduled SIM acquisition mode.

\section{$L O D(n g / g)$}

\begin{tabular}{lccccc}
\hline Herbicide & soil PO & soil CO & soil CA & soil CP & soil LT \\
Imazapyr & 10 & 14 & 12 & 9 & 11 \\
Imazamethabenz & 9 & 11 & 10 & 7 & 12 \\
Imazamethabenz Methyl & 4 & 8 & 5 & 4 & 7 \\
Imazaquin & 6 & 9 & 7 & 5 & 6
\end{tabular}

ratio of 3 (the ratio of the peak intensity and the intensity of the noise was used) are shown in table V. These limits of detection are considered adequate for the subsequent use of this method for environmental analysis.

\section{Acknowledgements}

Financial support of the C.N.R. (National Research Council) and of M.U.R.S.T. (Ministry for the University and for Scientific Research) is gratefully acknowledged.

\section{References}

1. Bailey, G.W.; White, J. L. Residue Rev. 1970, 32, 29-92.

2. Guth, J. A. In: Interaction between Herbicides and the Soil, Hance, R. J. Ed., Academic Press, London, 1980; pp 147-149.

3. Severn, D. J.; Ballard, G. In: Pesticides in the Soil Environment Processes, Impacts and Modeling, Cheng, H. H. Ed., Soil Science Society of America, Madison, WI, 1990; pp 472-476.

4. Shaner, D. L.; O'Connor, S. L. The Imidazolinone Herbicides, CRC Press, Boca Raton, FL., 1991.

5. Stout, S. J.; da Cunha, A. R.; Allardice, D. G. Anal. Chem. 1996, 68, 653-658.

6. Atienza, J.; Jimenez, J. J.; Herguedas, A.; Bernal, J. L. J. Chromatogr. A 1996, 721, 113-121.

7. Loux, M. M.; Liebl, R. A.; Slife, F. W. Weed Sci. 1989, 37, 259-267.

8. Liu, W.; Pusino, A.; Gessa, C. Sci. Total Environ. 1992, 123/124, 39-43.

9. D’Ascenzo, G.; Gentili, A.; Marchese, S.; Perret, D. Rapid Comm. in Mass Spectrom., in press.

10. Wehtje, G.; Dickens, R.; Wilcut, W.; Hajek, B. F. Weed Sci. 1987, 35, 858-864.

11. D’Ascenzo, G.; Gentili, A.; Marchese, S.; Perret, D. J. Chromatogr. A 1998, 800, 109-119. 